\title{
Effect of nitric oxide synthase inhibitor on allergen- and hyperventilation-induced bronchoconstriction in guinea-pigs
}

\author{
H. Nogami, E. Umeno, S. Kano, T. Hirose, S. Nishima
}

Effect of nitric oxide synthase inhibitor on allergen- and hyperventilation-induced bronchoconstriction in guinea-pigs. H. Nogami, E. Umeno, S. Kano, T. Hirose, S. Nishima. CERS Journals Ltd 1998.

ABSTRACT: To elucidate the role of endogenous nitric oxide (NO) in allergen- (AIB) and hyperventilation-induced bronchoconstriction (HIB), the effects of an NO synthase inhibitor, $N^{\mathrm{G}}$-nitro-L-arginine methyl ester (L-NAME), on AIB and HIB were studied in guinea-pigs.

In the AIB group, 21 anaesthetized guinea-pigs, actively sensitized with $1 \%$ ovalbumin, were challenged with aerosolized $0.1 \%$ ovalbumin solution under mechanical ventilation. In the HIB group, 14 guinea-pigs were challenged with hyperventilation (tidal volume of $12 \mathrm{~mL} \cdot \mathrm{kg}^{-1}$ at 150 breaths $\cdot \mathrm{min}^{-1}$ with $21 \% \mathrm{O}_{2}$ and $5 \% \mathrm{CO}_{2}$ dry gas) for $5 \mathrm{~min}$. In both groups, lung resistance $(R \mathrm{~L})$ was measured using a pressure-volumesensitive body plethysmograph, with or without $\mathrm{L}-\mathrm{NAME}$ pretreatment $\left(8 \mathrm{mg} \cdot \mathrm{kg}^{-1}\right.$ i.v.

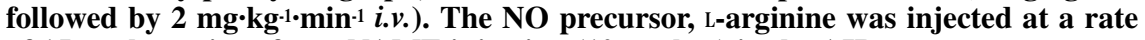
of $15 \mathrm{mg} \cdot \mathrm{kg}^{-1} \cdot \mathrm{min}^{-1}$ after $\mathrm{L}-\mathrm{NAME}$ injection $\left(10 \mathrm{mg} \cdot \mathrm{kg}^{-1}\right)$ in the AIB group.

The results were as follows. In the AIB group, the maximal $R \mathrm{~L}$ change was significantly potentiated by pretreatment with $L-N A M E$. This potentiating effect of $\mathrm{L}-$ NAME was reversed by L-arginine. In the HIB group, the pretreatment with L-NAME had no effect on increases in $R L$.

These findings suggest that endogenous nitric oxide may play an important role in the modulation of allergen-, but not hyperventilation-induced bronchoconstriction in guinea-pigs.

Eur Respir J 1998; 12: 1318-1321.
Clinical Research Institute, National Minami Fukuoka Chest Hospital, Fukuoka, Japan.

Correspondence: T. Hirose

Clinical Research Institute

National Minami Fukuoka Chest Hospital 4-39-1 Yakatabaru

Minamiku, Fukuoka 811-1394

Japan

Fax: 81925660702

Keywords: Allergen-induced bronchoconstriction

hyperventilation-induced bronchoconstriction

nitric oxide

nitric oxide synthase

$\mathrm{N}^{\mathrm{G}}$-nitro-L-arginine methyl ester

Received: August 111997

Accepted after revision July 151998
Airway hyperresponsiveness and bronchoconstriction are induced by a wide variety of agents in bronchial asthma [1]. Allergen-induced bronchoconstriction (AIB) is mediated by chemical mediators derived from mast cells [2], while hyperventilation-induced bronchoconstriction (HIB) is reported to be associated with tachykinin release [3].

BARNES and coworkers [4] reported that nitric oxide (NO) increases bronchial inflammation because the exhal-ed NO concentration in asthmatic patients was higher than that of healthy people. NO is released from a number of cells in the lung $[5,6]$ and may act to modulate pulmonary response to bronchoconstrictor agents, partly as a neurotransmitter of inhibitory nonadrenergic, noncholinergic nerves in airways [7].

The pathophysiological significance of endogenous NO remains controversial. NIJKAMP et al. [8] reported that endogenous NO may act as a bronchodilator $[8,9]$, because the nitric oxide synthase (NOS) inhibitor which inhibits endogenous NO production by competition with the NO precursor, L-arginine, increases histamine-induced bronchoconstriction in guinea-pigs. $N^{\mathrm{G}-N i t r o-L-a r g i n i n e ~ m e t h y l ~}$ ester (L-NAME), an NOS inhibitor, potentiated the tracheal response to histamine in vitro [8], but did not change the responsiveness to leukotriene $\mathrm{D}_{4}$, serotonin or cholinergic agonists [10]. Although tachykinin has been thought to be an important bronchoconstrictor factor in HIB, the pathophysiological role of endogenous NO in HIB as a potential bronchodilator is still unknown. The purpose of the present study was to elucidate the role of NO in AIB and HIB in guinea-pigs.

\section{Materials and methods}

\section{Anaesthesia and measurement of pulmonary resistance}

Thirty-five male Hartley-outbred guinea-pigs (Kyudo Co., Saga, Japan) weighing 390-490 g were anaesthetized intraperitoneally with sodium pentobarbital $\left(50 \mathrm{mg} \cdot \mathrm{kg}^{-1}\right)$. All animals were then ventilated with a constant-volume ventilator (Rodent ventilator model 683; Harvard Apparatus, Mills, MA, USA) delivering a tidal volume of 8 $\mathrm{mL} \cdot \mathrm{kg}^{-1}$ at a frequency of 60 breaths $\cdot \mathrm{min}^{-1}$ via a tracheal cannula. A polyethylene catheter was inserted into the left jugular vein for the administration of intravascular medication. The animals were then placed in a pressure-volume-sensitive body plethysmograph. Lung resistance $(R \mathrm{~L})$ was measured according to the method of SoRKNess et al. [11]. In brief, changes in transpulmonary pressure were measured using a Gould P231D transducer (Gould Instruments, Cleveland, $\mathrm{OH}$, USA) connected to a water-filled oesophageal cannula. Tidal airflow was measured with a pneumotachograph (Fleish 0000; Fleish, Lausanne, Switzerland) coupled with a Validyne MP45-16 Differential Pressure Transducer (Validyne Corp., Northridge, CA, 
USA). Tidal volume was obtained via electronic integration of the flow signal (Pulmonary Mechanics Analyzer, Model 6; Buxco Electronics, Sharon, CT, USA). RL signals of pressure and flow were monitored on a Nihon Koden four-channel recorder and were also delivered to an analogue computer (Pulmonary Mechanics Analyzer, Model 6; Buxco) to determine breath-by-breath values for the entire breath, using a covariance method (Buxco Program 3).

\section{Allergen-induced bronchoconstriction group}

The protocol for the allergen challenge is shown in figure 1 . Active sensitization by $1 \%$ ovalbumin inhalation for 30 min was performed on days 0 and 7 . Allergen challenges

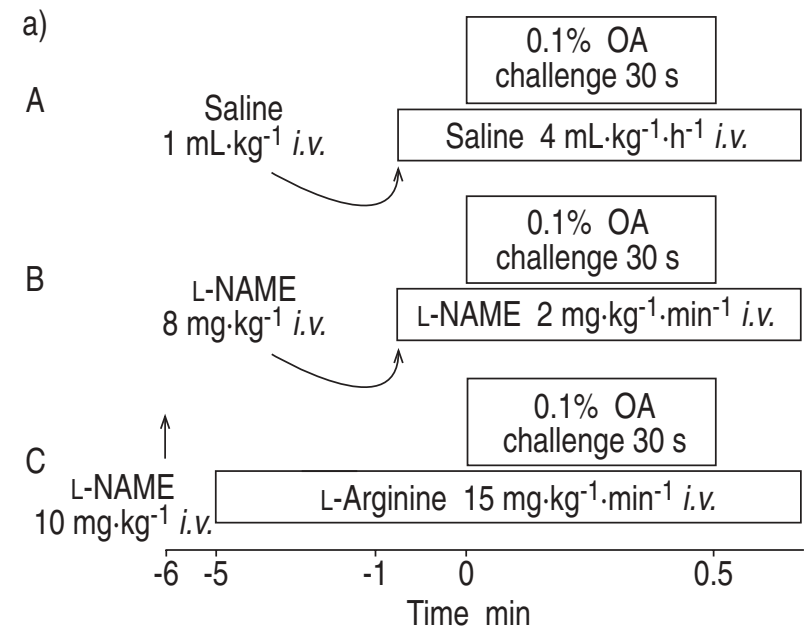

b)
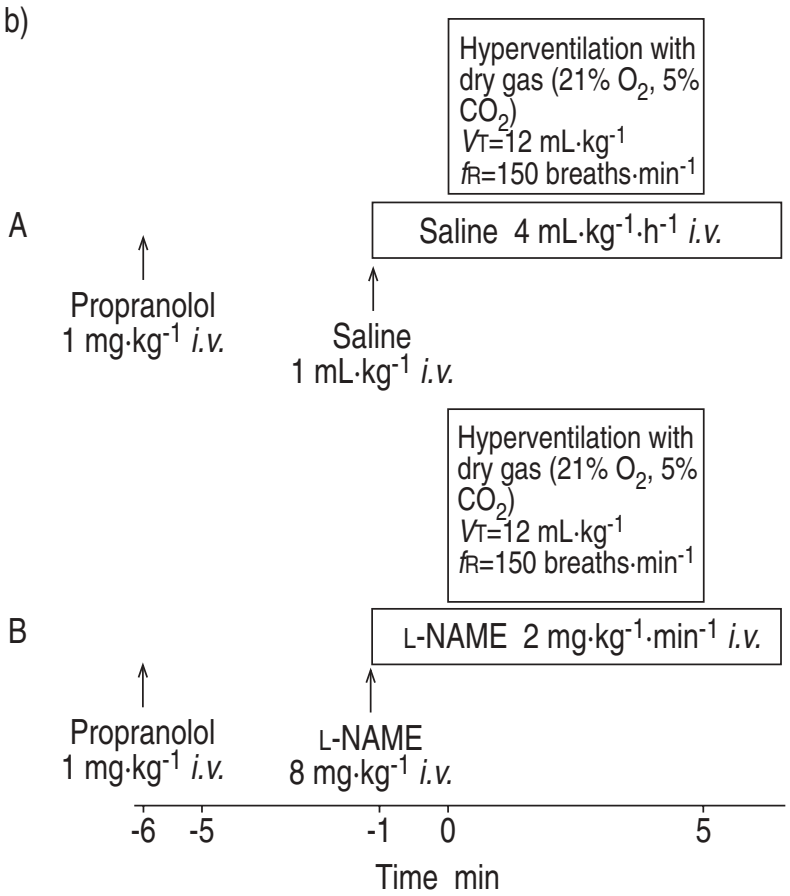

Fig. 1. - Protocols of a) allergen and b) hyperventilation challenges. Sensitization with $1 \%$ ovalbumin (OA; inhalation for $30 \mathrm{~min}$ ) was performed on days 0 and 7 . The challenges were conducted on day 14. A: control group $(\mathrm{n}=7)$; $\mathrm{B}: N^{\mathrm{G}}$-nitro-L-arginine methyl ester (L-NAME) group $(n=7) ; C$ : L-NAME + L-arginine group $(n=7)$. VT: tidal volume; $f \mathrm{R}$ : respiratory frequency. using inhalation of $0.1 \%$ ovalbumin for $30 \mathrm{~s}$ were conducted on day 14. In the control group $(n=7)$, normal saline was initially injected $\left(1 \mathrm{~mL} \cdot \mathrm{kg}^{-1}\right) 1 \mathrm{~min}$ before allergen challenge, followed by continuous infusion $\left(4 \mathrm{~mL} \cdot \mathrm{kg}^{-1} \cdot \mathrm{h}^{-1}\right)$ throughout the experiments. In the L-NAME group $(n=7)$, L-NAME diluted with saline was injected $\left(8 \mathrm{mg} \cdot \mathrm{kg}^{-1}\right.$ i.v. followed by $2 \mathrm{mg} \cdot \mathrm{kg}^{-1} \cdot \mathrm{min}^{-1} i$.v.) instead of saline. To assess whether or not L-arginine could reverse the effect of L-NAME, L-arginine was continuously infused at a rate of $15 \mathrm{mg} \cdot \mathrm{kg}^{-1} \cdot \mathrm{min}^{-1}$ during the experiments from $1 \mathrm{~min}$ after L-NAME (10 $\left.\mathrm{mg} \cdot \mathrm{kg}^{-1}\right)$ injection, followed by allergen challenges (L-arginine group; $\mathrm{n}=7$ ) 5 min later.

\section{Hyperventilation-induced bronchoconstriction group}

The protocol for the hyperventilation challenge is also shown in figure 1. Hyperventilation challenges (tidal volume of $12 \mathrm{~mL} \cdot \mathrm{kg}^{-1}$ at 150 breaths $\cdot \mathrm{min}^{-1}$ with $21 \% \mathrm{O}_{2}$ and $5 \% \mathrm{CO}_{2}$ dry gas) were performed for $5 \mathrm{~min}$ with and without pretreatment with L-NAME, using the same doses as the allergen challenge protocol. Normal saline (control group; $n=7$ ) or L-NAME (L-NAME group; $n=7$ ) was given $1 \mathrm{~min}$ before the challenge. According to the method of RAY et al. [3], each guinea-pig received propranolol (1 $\mathrm{mg} \cdot \mathrm{kg}^{-1}$ i.v.) 6 min before the challenge to minimize potential changes in bronchoconstrictor response resulting from changes in the levels of circulating catecholamines. No change in $R \mathrm{~L}$ resulted from this infusion.

\section{Drugs}

The following drugs were used for the experiments: sodium pentobarbital (Dainippon Pharmaceutical Co., Osaka, Japan), propranolol hydrochloride (Sumitomo Pharmaceuticals, Osaka), L-NAME, L-arginine hydrochloride and ovalbumin (Sigma Chemical Co., St Louis, MO, USA).

\section{Statistical analysis}

$R \mathrm{~L}$ values are expressed as median and range. Because most of the data were not normally distributed, statistical analysis was performed using the nonparametric KruskalWallis test for differentiation among the groups in the AIB. When this test indicated significant differences, each pairing was examined by means of the Mann-Whitney Utest. In HIB, the Mann-Whitney U-test for two groups was used. A p-value $<0.05$ was taken as statistically significant.

\section{Results}

There were no significant differences in baseline $R \mathrm{~L}$ before each challenge between the groups (the median values of $R \mathrm{~L}$ ranged $\left.0.177-0.195 \mathrm{cmH}_{2} \mathrm{O} \cdot \mathrm{mL}^{-1} \cdot \mathrm{s}^{-1}\right)$.

Effect of L-NAME and L-arginine on allergen-induced bronchoconstriction

The time course of the increase in $R \mathrm{~L}$ in allergen challenge is shown in figure 2 . The values of baseline $R \mathrm{~L}$ were $0.188(0.175-0.228)$ in the control group, $0.180(0.175-$ $0.200)$ in the L-NAME group and $0.195(0.178-0.220)$ 


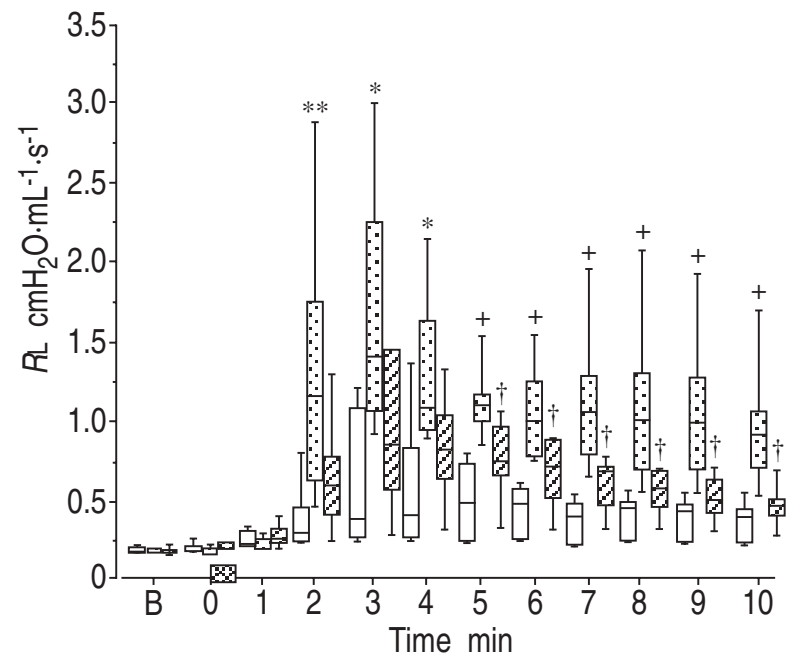

Fig. 2. - Time course of increase in lung resistance $(R \mathrm{~L})$ values after $0.1 \%$ ovalbumin inhalation ( $\mathbb{Q}$ ) for $30 \mathrm{~s}$ in guinea-pigs. Animals were pretreated with saline (control group: $\square, \mathrm{n}=7$ ), $N^{\mathrm{G}}$-nitro-L-arginine methyl ester (L-NAME group: $\because \because, \mathrm{n}=7$ ) or L-NAME and L-arginine (Larginine group: $Q, \mathrm{n}=7$ ). Data are expressed as median and range. $\mathrm{B}$ : baseline. *: $\mathrm{p}<0.05, * *: \mathrm{p}<0.01,+: \mathrm{p}<0.005$ compared with the control

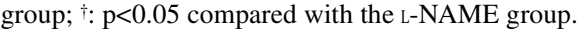

$\mathrm{cmH}_{2} \mathrm{O} \cdot \mathrm{mL}^{-1} \cdot \mathrm{s}^{-1}$ in the L-arginine group. There were no significant differences among these three groups. Although $R \mathrm{~L}$ was significantly increased after challenges in all groups, pretreatment with L-NAME potentiated AIB significantly (from 2-10 min after challenge) compared with controls. However, this effect was reversed by L-arginine. There were significant differences in the $R \mathrm{~L}$ values from 5-10 min after challenge between the L-NAME and Larginine groups. Although a maximal $R \mathrm{~L}$ change in the control group $\left(0.513(0.275-1.613) \mathrm{H}_{2} \mathrm{O} \cdot \mathrm{mL}^{-1} \cdot \mathrm{s}^{-1}\right)$ was significantly potentiated by pretreatment with L-NAME to 2.065 (1.105-3.895), L-arginine significantly reduced this potentiation of maximal change to $1.003(0.338-1.763)$ $\mathrm{cmH}_{2} \mathrm{O} \cdot \mathrm{mL}^{-1} \cdot \mathrm{s}^{-1}(\mathrm{p}<0.03)$.

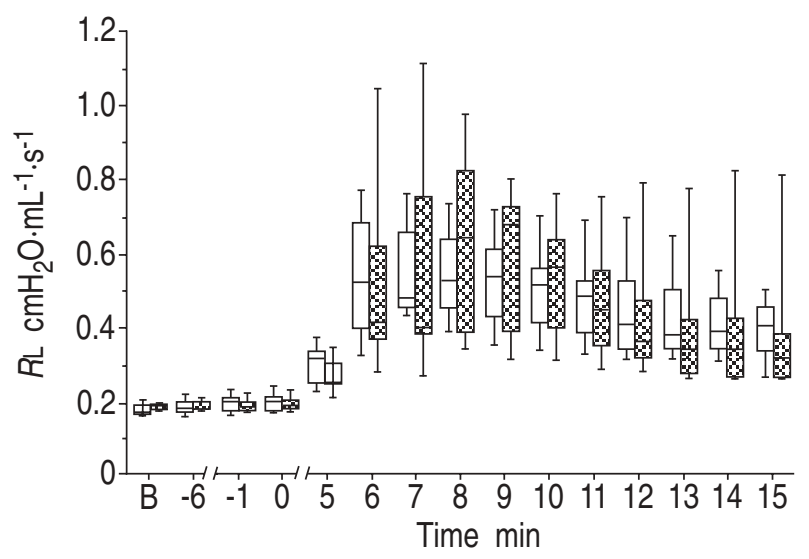

Fig. 3. - Time course of increase in lung resistance $(R \mathrm{~L})$ values after hyperventilation challenge. Animals were pretreated with saline (control group: $\square, \mathrm{n}=7$ ) or $N^{\mathrm{G}}$-nitro-L-arginine methyl ester (L-NAME group: $\$, n=7)$. B: baseline. Data are expressed as median and range.
Effect of L-NAME on hyperventilation-induced bronchoconstriction

The time course of the increase in $R \mathrm{~L}$ in hyperventilation challenge is shown in figure 3 . The values of baseline $R \mathrm{~L}$ were $0.177(0.165-0.213)$ in the control group and $0.193(0.175-0.200) \mathrm{cmH}_{2} \mathrm{O} \cdot \mathrm{mL}^{-1} \cdot \mathrm{s}^{-1}$ in the L-NAME group. There were no significant differences in the increase in $R \mathrm{~L}$ between the two groups. L-NAME pretreatment did not potentiate the maximal increase in $R \mathrm{~L}$ in HIB, which was $0.575(0.495-0.830)$ in the control group and 0.688 $(0.400-1.255) \mathrm{cmH}_{2} \mathrm{O} \cdot \mathrm{mL}^{-1} \cdot \mathrm{s}^{-1}$ in the L-NAME group.

\section{Discussion}

In the present study, L-NAME, an NOS inhibitor, potentiated AIB, but not HIB. In addition, the NO precursor, L-arginine, attenuated the potentiation of AIB induced by the NOS inhibitor. These results indicate that endogenous NO may have a protective effect on AIB, but not on HIB. The effect of L-NAME on pulmonary circulation may be small, because administration of the drug itself did not influence the baseline $R \mathrm{~L}$ values.

Several studies have supported these results. NiJKamp et al. [8] reported that endogenous NO had a protective effect on histamine-induced bronchoconstriction in guineapigs. They also observed that NO was constitutively synthesized by NOS in the bronchial epithelium. Recently, RICCIARDOLO et al. [12] reported that endogenous NO reduced bronchoconstriction caused by inhaled bradykinin in subjects with mild asthma. Their study also showed that the inhibition of the NOS pathway potentiated bronchoconstriction caused by inhaled methacholine. PERSSON et al. [9] showed that an NOS inhibitor augmented AIB, and the inhalation of NO reversed the increase in insufflation pressure. The present study with L-arginine confirms, the role of endogenous NO in the protection of AIB. In vitro and in vivo, L-NAME competitively inhibits NOS, an effect which can be reversed by the addition of L-arginine [13]. NIJKAMP et al. [8] reported that L-arginine inhibited the potentiation of histamine-induced bronchoconstriction by L-NAME in guinea-pigs.

There have also been several controversial reports. BARNES and coworkers [4] showed that the concentrations of exhaled NO were higher in asthmatic patients than in normal controls, and suggested that NO may have proinflammatory effects. A pathophysiological role of endogenous NO in asthma, however, remains to be elucidated. BARNES and coworkers [4] reported that NO is produced by inducible NOS (iNOS) during the late asthmatic response, because steroid inhalation can decrease the concentration of NO in asthmatic subjects. iNOS is tonically activated, independently of $\mathrm{Ca}^{2+}$ and under the transcriptional control of pro-inflammatory cytokines, such as interferon-gamma (IFN- $\gamma$ ), interleukin-1 $\beta$ (IL-1 $\beta$ ) and tumour necrosis factor-alpha (TNF- $\alpha$ ). Pulmonary iNOS has been described in endothelial and epithelial cells and in macrophages of inflamed airways, and its induction results in the production of high (micromolar) levels of NO. However, B0ER et al. [14] suggested that contractile agonists, such as histamine, enhanced the production of constitutive NOS (cNOS), and not iNOS. cNOS, in the airways, is 
basally expressed in neuronal, endothelial and epithelial cells and its activation is dependent on an agonist- or depolarization-induced increase in intracellular $\mathrm{Ca}^{2+}$ concentration, causing the production of small (picomolar) amounts of NO.

The NO produced by allergen challenge may originate from constitutive NO synthase, since the increase in $\mathrm{NO}$ is an immediate reaction, while the inducible enzyme needs a few hours to be induced [15]. Although the present findings do not provide a conclusive explanation for the potentiation of allergen-induced immediate bronchoconstriction by the NOS inhibitor, an allergen or allergeninduced mediator such as histamine and bradykinin may activate the constitutive NOS pathway in this experiment.

In HIB, RAY et al. [3] reported that tachykinin was an important bronchoconstrictor in guinea-pigs, because the response was blocked by pretreatment with capsaicin and was increased by phosphoramidon, an inhibitor of neutral endopeptidase, which is a degrading enzyme for tachykinin. Previous studies also reported that during hyperventilation challenge, histamine did not increase in either the bronchoalveolar lavage or blood of guinea-pigs [1618]. The present study shows that, in contrast to allergen challenge, the NOS inhibitor had no protective effect on $\mathrm{HIB}$, indicating that NO does not act in HIB; for this reason, L-arginine was not administered for HIB. These findings suggest that tachykinins such as substance $\mathrm{P}$ and neurokinin A are important bronchoconstrictors, while endogenous NO is less important as a bronchodilator during hyperventilation challenge, in contrast to AIB.

In conclusion, $N^{\mathrm{G}}$-nitro-L-arginine methyl ester, a nit- ric oxide synthase inhibitor, potentiated allergen-induced bronchoconstriction, but not hyperventilation-induced bronchoconstriction. Furthermore, the nitric oxide precursor Larginine attenuated the potentiation of allergen-induced bronchoconstriction induced by the nitric oxide synthase inhibitor. These results indicate that endogenous nitric oxide may have a protective effect on allergen-induced bronchoconstriction, but not on hyperventilation-induced bronchoconstriction. Further study will be needed to clarify the origin of the nitric oxide and a pathophysiological significance of endogenous nitric oxide release in asthma.

\section{References}

1. O'Byrne PM. Airway hyperresponsiveness. In: Middleton E Jr, Reed CE, Ellis EF, Adkinson NF Jr, Yunginger JW, Busse WW, eds. Allergy Principles and Practice. 4th Edn. St Louis, Mosby, 1993; pp. 1203-1213.

2. Bukantz SC, Lockey RF. IgE immediate hypersensitivity. In: Weiss EB, Stein M, eds. Bronchial Asthma: Mechanism and Therapeutics. 3rd Edn. Boston, Little, Brown \& Co., 1993; pp. 68-79.

3. Ray DW, Hernandez C, Leff AR, Drazen JM, Solway J.
Tachykinin mediated bronchoconstriction elicited by isocapnic hyperpnea in guinea pigs. J Appl Physiol 1989; 66: 1108-1112.

4. Kharitonov SA, Yates D, Robbins RA, Logan-Sinclair R, Shinebourne EA, Barnes PJ. Increased nitric oxide in exhaled air of asthmatic patients. Lancet 1994; 343: 133135.

5. Anggard E. Nitric oxide: mediator, murderer, and medicine. Lancet 1994; 343: 1199-1206.

6. Moncada S, Palmer RMJ, Higgs EA. Nitric oxide: physiology, pathophysiology, and pharmacology. Pharmacol Rev 1991; 327: 109-142.

7. Bervisi MG, Stretton CD, Miura M, et al. Inhibitory NANC nerves in human tracheal smooth muscle: a quest for the neurotransmitter. J Appl Physiol 1992; 73: 25052510.

8. Nijkamp FP, Linde HJ, Folkerts G. Nitric oxide synthesis inhibitors induce airway hyperresponsiveness in guinea pig in vivo and in vitro: role of the epithelium. Am Rev Respir Dis 1993; 148: 727-734.

9. Persson MG, Friberg SG, Hedqvist P, Gustafsson LE. Endogenous nitric oxide counteracts antigen-induced bronchoconstriction. Eur J Pharmacol 1993; 249: R7-R8.

10. Leurs E, Brozium MM, Jansen W, Bast A, Timmerman H. Histamine H1-receptor-mediated cyclic GMP production in guinea pigs lung tissue is an L-arginine-dependent process. Biochem Pharmacol 1991; 42: 271-277.

11. Sorkness R, Blythe S, Lemanske RF Jr. Pulmonary antigen challenge in rats passively sensitized with a monoclonal IgE antibody induces immediate but not late changes in airway mechanics. Am Rev Respir Dis 1988; 138: 11521156.

12. Ricciardolo FLM, Geppetti P, Mistretta A, Nadel JA, Sapienza MA, Bellofiore S. Randomized double-blind placebo controlled study of the effect of inhibition of nitric oxide synthesis in bradykinin-induced asthma. Lancet 1996; 348: 374-377.

13. Marletta MA, Tayeh MA, Hevel JM. Unraveling the biological significance nitric oxide. Biofactors 1990; 2: 219225.

14. Boer J, Meurs H, Coers W, et al. Deficiency of nitric oxide in allergen-induced airway hyperreactivity to contractile agonists after the early asthmatic reaction: an $e x$ vivo study. Br J Pharmacol 1996; 119: 1109-1116.

15. Nijkamp FP, Folkerts G. Nitric oxide and bronchial hyperresponsiveness. Arch Int Pharmacodyn 1995; 329: 81-96.

16. Barnes PJ, Brown MJ. Venous plasma histamine in exercise and hyperventilation-induced asthma in man. Clin Sci 1981; 61: 159-162.

17. Farley RD, Albazzaz MK, Patel KR. Role of cooling and drying in hyperventilation induced asthma. Thorax 1988; 43: 289-294.

18. Nagakura T, Lee TH, Assufi BK, Denison DM, NewmanTaylor AJ, Kay AB. Neutrophil chemotactic factor in exercise- and hyperventilation-induced asthma. Am Rev Respir Dis 1983; 128: 294-296. 